\title{
Impact of Blog Design Features on Blogging Satisfaction: An Impression Management Perspective
}

\author{
Wee-Kek Tan and Hock-Hai Teo \\ Dept. of Information Systems, National University of Singapore, \\ 21 Lower Kent Ridge Road, Singapore 119077, Republic of Singapore \\ \{tanwk, teohh\}@comp.nus.edu.sg
}

\begin{abstract}
Trends observed among bloggers worldwide suggest that selfpresentation is a main motivation to blog and a greater majority of bloggers do so with the aid of third party hosting services and tools. Thus, providing tools that are designed to meet the usability requirement of bloggers with respect to self-presentation may increase blogging satisfaction. Grounded on the theory of impression management, we propose that a blogger actively engages in impression management with content, functional and aesthetic blog design features. This can lead the blogger to obtain a perceived confirmation from the readers of his or her identity, i.e., perceived identity verification. Perceived identity verification may heighten blogging satisfaction since it helps the blogger to achieve the goal of self-presentation. Results obtained from an online survey, which was preceded by a focus group discussion, provide support for our conjecture. Theoretical and practical implications are also discussed.
\end{abstract}

Keywords: Blog, blog design features, satisfaction, self-presentation, theory of impression management.

\section{Introduction}

Blogging is a highly popular online activity. According to survey statistics from the State of the Blogosphere 2009 [1], the majority of bloggers on the Internet are casual bloggers who seek to express their life, and to share their expertise and experience. Beyond personal motivations, there is also a growing trend in using blog to make money and to exert political influence. These wide-ranging impacts are being wielded by the majority of bloggers using third party hosting services and tools [1]. It is therefore important to develop an in-depth understanding of how blog tools may be designed to meet the usability requirements of bloggers [2].

Since the majority of bloggers use their blog to express their life and personality in the form of online journal [3], i.e. self-presentation, it makes sense to provide design features that support this main motivation. To this extent, functional features to aid in blogging and the ability to customize the blog's aesthetic elements are two key factors affecting bloggers' choice of third party tools [1]. Moreover, most bloggers consider personal satisfaction as the key success measure of their blogs [1]. This research thus 
examines how content, functional and aesthetic design features of blog, which aid the blogger in achieving self-presentation, may affect blogging satisfaction.

The findings from this research can potentially help researchers and practitioners to design effective blogging tools. Besides blog hosting service providers such as Blogger, social networking sites such as Friendster that incorporate blogging as a pertinent feature may also benefit from this research.

\section{Theoretical Background}

Bloggers typically express their identity on their blogs in the form of personal information such as age and location, emoticons, language styles, occupations, and hobbies. Over a period of time, it is possible for a blogger to develop virtual identity [4]. One fundamental theoretical notion underpinning this process is that individuals proactively present their identity to others using props as explained by the theory of impression management.

\subsection{Theory of Impression Management}

The impressions that individuals leave on other people typically affect how they are perceived, evaluated and treated [5]. Consequently, individuals are inclined to control the impressions that others form of them, i.e., impression management. According to the theory of impression management, this process draws a metaphoric similarity with theatrical performance [6]. In a performance that takes place in a public setting, the actor prepares the required props and scenery in the back-stage before performing with the props and scenery on-stage. In a similar fashion, an individual makes a conspicuous effort to acquire knowledge, skill and props so that $\mathrm{s} / \mathrm{he}$ can use them to project certain impression upon other people.

\subsection{Impression Management on the Web}

Researchers have found that personal home pages are being used by their authors to publish information on topics deemed important to them together with their social contexts [7]. To this extent, personal home page is an inclusive self-presentation tool that explicates the identity of its author [8]. Indeed, the author of a personal website makes a conspicuous effort to adorn his or her web pages with identity claims that present a coherent online identity [9]. The identity claims could include textual and non-textual contents reflecting the interests, preferences and values of the author, i.e., the props [6]. For instance, aesthetic elements (e.g., image, video and sound) and functional elements (e.g., hyperlink to website related to the author's interest).

\subsection{Blog Design Features for Impression Management}

Within the context of blog, self-presentation may be applied by bloggers through the creation or usage of blog template and manipulation of the underlying Hypertext Markup Language (HTML) code [10]. Our present study, however, goes beyond the use of basic website elements such as image and hyperlink to examine how 
sophisticated functional and aesthetic blog design features provided by third party service providers can be used for self-presentation. We shall term this as impression management with blog design features. Functional features such as blogger profile and blogroll are required for bloggers to share their life and experiences with readers. Aesthetic features such as blog header and background enhance the visual appeal of the blog and sustain readers' interest.

In addition, the most important characteristic of blog is the posting of journal entries in a reverse chronological order by the author. Most third party blog tools aim to automate this process in the simplest way possible [2]. For this reason, we consider the content feature as another important dimension of blog design. Content feature aids the blogger in posting both textual and non-textual materials that reflect his or her identity over and above what the functional features can accomplish. In gist, content, functional and aesthetic design features collectively make up the props required by the blogger to present his or her identity to the readers. Fig. 1 depicts sample screenshots of the three categories of blog design features currently available on third party blog service providers.

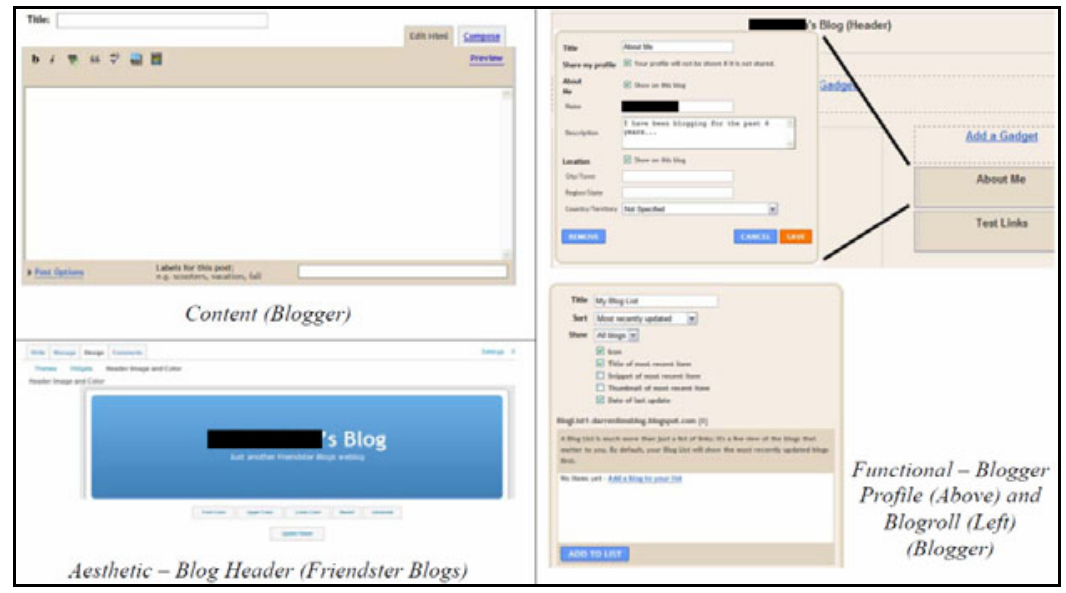

Fig. 1. Screenshots of blog design features

\subsection{Presentational Expectancies}

Although the theory of impression management explains how bloggers could use the various blog design features as props to present their identities, there is a non-trivial caveat that needs to be taken into consideration. Researchers have noted that social anxiety could develop if an individual is motivated to make a desired impression to a target audience but is hesitant that s/he has the capability to do so [11]. That is, an individual's self-presentation behavior can be affected by presentational outcome expectancy and presentational self-efficacy expectancy [11, 12]. The former refers to the belief that projecting certain impression will lead to the desired goal and the latter refers to the belief on one's ability to present that impression. 


\section{Research Model and Hypotheses Development}

Drawing on the theory of impression management as the theoretical lens, we put forth our research model (see Fig. 2) to understand how the provision of various blog design features may fulfill the usability requirement of bloggers in term of impression management.

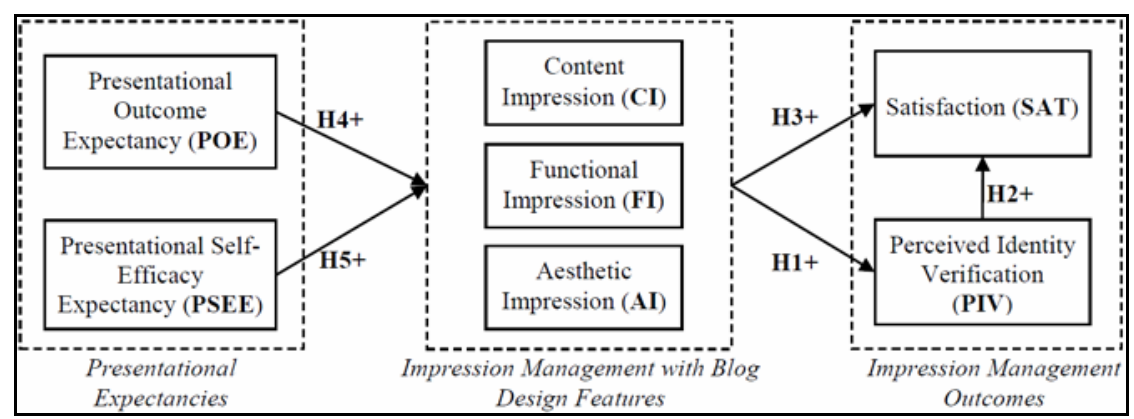

Fig. 2. Research model

\subsection{Impression Management Process and Its Impacts}

In a technology-mediated setting, tools that facilitate rich social interaction can aid in achieving shared understanding among the communicating parties [13], which is helpful for identity communication. In particular, personal website has often been heralded as a new form of identity communication [14].

Prior research has suggested that it is possible for personal website to communicate nonverbal cues through the use of hyperlinks, emotions, animations and other technological conventions [15]. Collectively, these website elements form the props for individuals to present themselves to the public using the personal websites as the performing stage [6]. In a similar fashion, bloggers are known to present themselves through their blogs [10]. A blogger actively using the various content, functional and aesthetic design features can put across his or her desired impression in a consistent and focused manner to readers of their blog. This can give the blogger a perceived confirmation from the readers of his or her identity, i.e., perceived identity verification [16]. We thus hypothesize that:

H1: Impression management with blog design features is positively related to perceived identity verification.

In an online community, members whose identities are verified and recognized by others will feel that they are better understood and will be treated in the desired way [16]. Thus, communications among members should have lesser misunderstandings and conflicts. Furthermore, members will be inclined towards increasing their attraction to other community members and commitment to the online community [17]. In a real world setting, identity verification can lead to a satisfying interpersonal relationship because of the resulting shared understanding forged through the verification process [18]. 
In sum, identity verification should lead to contentment with an individual access to community resources, i.e., satisfaction [16]. In our context, we define satisfaction as whether the blogger is contented with the blogging experience to express one's life and to share one's expertise and experience with the readers. Accordingly, we hypothesize that:

H2: Perceived identity verification is positively related to satisfaction.

We also propose a second direct causal pathway between impression management and perceived identity verification. In an online community, identity communication can often help members to connect to others who share similar interests, attitudes and experiences [19]. People with similar personality are more likely to communicate and build relationships [20]. Impression management aids the blogger to present their identity to the readers and thus attracts those who share similar identity. It thus aid bloggers to achieve their goals of expressing themselves and share their experiences and expertise with similar others. Indeed, it is possible for bloggers and their readers to form a community of similar interest [3].

Satisfaction may be viewed as a positive affective arousal on the part of the blogger towards his or her blogging experience [21]. It may be induced in the presence of an advancement factor that brings the blogger closer to the attainment of the self-presentation goal [22]. We posit that impression management with the aid of content, functional and aesthetic design features constitute this advancement factor. We thus hypothesize that:

H3: Impression management with blog design features is positively related to satisfaction.

\subsection{Antecedents of the Impression Management Process}

Outcome and self-efficacy expectancies have been widely studied in the extant literature on individual's use of information technology (e.g., [23]). Both computer outcome and self-efficacy expectancies are known to reduce computer-related anxiety and increase computer usage [23]. Within the online context, Internet self-efficacy expectancy has also been found to enhance individuals' perception of the ease of use of Internet technology and consequently higher behavioral intention and actual usage behavior [24].

In this study, we adapt the original conceptualization of presentational outcome and self-efficacy expectancies $[12,25]$ to the context of the blogger using blog design features to manage one's impression. Presumably, high degree of presentational expectancies should reduce a blogger's anxiety towards the use of the various blog design features to manage his or her impression and consequently increase their propensity to do so [12]. Accordingly, we put forth our final two hypotheses:

H4: Presentational outcome expectancy is positively related to impression management with blog design features.

H5: Presentational self-efficacy expectancy is positively related to impression management with blog design features. 


\section{Research Methodology}

\subsection{Research Design}

This study primarily adopted a quantitative survey design to empirically validate the research model depicted in Fig. 2. Specifically, an online survey technique was used for two reasons: 1) an online survey would have been more convenient for bloggers to participate; and 2) online survey allowed us to administer visual stimuli for the various blog design features to enhance the questionnaire.

In addition, we conducted an initial focus group discussion with a group of experienced local bloggers to help us gather insights on two issues. First, we wanted to determine whether the majority of local bloggers do indeed blog to express their life, and share their expertise and experience, as reported by the State of the Blogosphere 2009 [1]. Second, we wanted to determine the blog design features that the bloggers would most likely use for impression management. This was to aid us in preparing a representative set of features for the visual stimuli of the survey questionnaire.

\subsection{Focus Group}

The focus group was conducted with ten bloggers over two sessions of five bloggers each. They were recruited through an online invitation posted on the website of a popular online community for local bloggers. The proceedings of the discussion were audio recorded and transcribed subsequently.

In the first part, the participants were asked to share their motivations for blogging and the types of contents posted on their blog. Consistent with the findings of the State of the Blogosphere 2009, six out of ten participants explicitly mentioned selfpresentation as well as experience and expertise sharing as the main motivation for blogging: "I use my blog as a diary that is opened to others, especially my friends and family...; I write just about anything that happened to me on my blog..." Three other participants indirectly hinted at self-presentation as their blogging motivation: "I mostly gossip about what happened in the office...; I give my takes on current affairs, well sometimes I grumbled about bread and butter issues..."

In the second part, we explained to the participants the purpose of the focus group and also gave them an overview of content, functional and aesthetic blog design features. We then asked the participants to discuss how these features may be used for self-presentation. Most participants highlighted the content feature as the most useful and obvious one in expressing their identity: "I feel that the content of the blog is usually detailed enough to show my identity..." Aesthetic design features were also given the thumbs up: "I make extensive changes to my blog template to reflect my favorite color, hobby and idols..." Functional design features drew mixed responses. Most participants, however, pointed out that certain features were useful: "I placed many links to other blogs and websites associated with my idols... I guess that counts as some form of social affiliation...; the short blogger profile says everything about me..."

Towards the end, the participants were asked to rank the various features in descending order of suitability for self-presentation. Various functional and aesthetic design features were identified from the extant literature (e.g., [26]) and given to the participants. Those features with a ranking score greater than the mean were used in the subsequent survey questionnaire as visual stimuli (see Table 1). 
Table 1. Selected functional and aesthetic design features used in the online survey

\begin{tabular}{lrrlrr}
\hline Functional & Mean & Std. Dev. & Aesthetic & Mean & Std. Dev. \\
\hline Blogger Profile & 18.0 & 3.300 & Post Content & 10.7 & 1.947 \\
Photo Albums & 16.7 & 3.129 & Blog Header & 9.9 & 2.514 \\
Tagboard & 14.9 & 5.971 & Content Area & 9.0 & 1.700 \\
Links to Non-blog Websites & 14.8 & 2.860 & Post Title & 8.5 & 1.900 \\
Blogroll & 14.6 & 3.627 & Blog Background & 7.4 & 2.989 \\
Badge & 13.0 & 5.477 & Primary Navigation & 6.1 & 3.381 \\
\hline
\end{tabular}

\subsection{Operationalization of Constructs}

The theoretical constructs shown in the research model (see Fig. 2) were measured with instrument scales either adapted from validated scales or self-developed based on established definitions from the extant literature. Except for satisfaction, which is a seven-point semantic differential scale, the remaining constructs used seven-point Likert scales.

The scale measuring content impression was adapted from [27]. The scales for functional impression and aesthetic impression were self-developed based on the content impression scale. Presentational outcome expectancy and presentational selfefficacy expectancy were measured using scales adapted from [12] and [29]. Satisfaction was measured with a scale adapted from [28]. For the scale measuring perceived identity verification, we followed Ma and Agarwal's prescription [16].

\subsection{Survey Design and Procedure}

The online survey was conducted over a one month period and participants were recruited via an open invitation posted on the same online community. All participants were checked to ensure that they had an existing personal blog that was actively maintained for at least the past 12 months leading up to the survey.

The survey proceeded according to the following sequence. Participants first registered their particular and also undergone a simple validation of their blog. They then read the survey instructions before proceeding to read the description of each

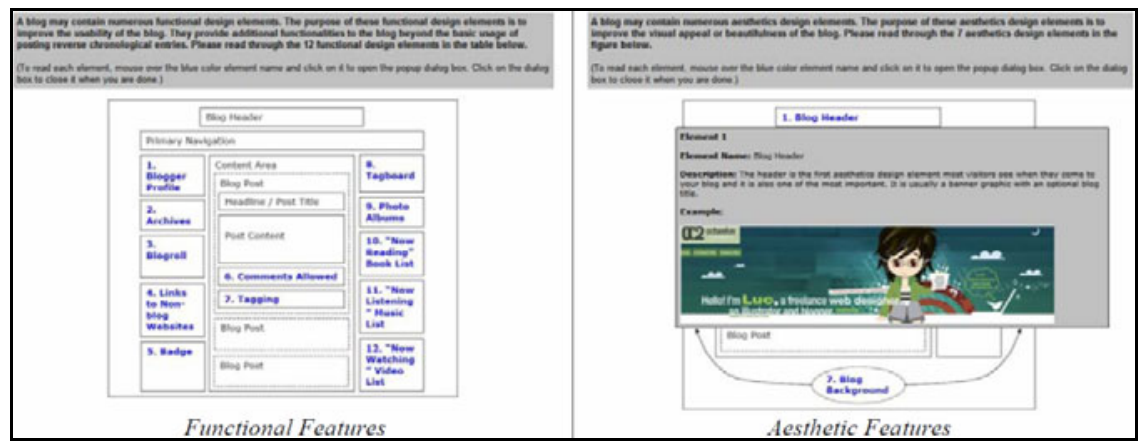

Fig. 3. Screenshots taken from actual survey website 
category of blog design features and view the associated visual stimuli. The visual stimuli were spread over three web pages, one per category of features. For content, the participants were shown a sample screenshot of a blog post editor taken from Blogger together with the preview of the post. For the functional and aesthetic features, the participants were shown a skeleton layout of a blog with the various features marked up (see Fig. 3).

Participants must view all features in each category before proceeding to the next category. The survey website ensured that they spent at least five minutes on each category to adequately understand the various features. The participants then proceeded to complete the main survey and a short demographic questionnaire. Most of the participants took less than 30 minutes to complete the entire survey.

\section{Results}

\subsection{Descriptive Statistics}

There were altogether 261 participants who registered. After removing the invalid responses, the final useable sample size was 244. There were 113 male and 131 female participants. The majority of the participants were aged from 21-30 (67.2\%) and were locals $(82.4 \%)$. On the average, the participants had 3.0 years of blogging experience $(\delta=2.232)$ and $66.4 \%$ of them blog on a daily or weekly basis.

\subsection{Validity and Reliability of Instrument Scales}

The data were analyzed with partial least square (PLS) based structural equation modeling. The internal consistency, convergent validity and discriminant validity of the measurement model were assessed to be acceptable. The instrument scales were also deemed to be reliable after assessing their Cronbach Alpha scores.

\subsection{Hypotheses Testing}

We then proceeded to test the structural model with the bootstrapping procedure. The standardized path coefficient, standard error and statistical significance are shown in Table 2. The $R^{2}$ for perceived identity verification is 0.203 , satisfaction is 0.237 , content impression is 0.381 , functional impression is 0.227 and aesthetic impression is 0.233 .

Table 2. Summary of hypotheses testing results

\begin{tabular}{|c|c|c|c|c|c|c|c|c|c|}
\hline \multicolumn{2}{|c|}{ Hypothesis } & Path & Std. Error & Sig. & \multicolumn{2}{|c|}{ Hypothesis } & \multirow{2}{*}{$\begin{array}{l}\text { Path } \\
0.257\end{array}$} & \multirow{2}{*}{$\begin{array}{r}\text { Std. Error } \\
0.070\end{array}$} & \multirow{2}{*}{$\frac{\text { Sig. }}{* * *}$} \\
\hline H1 & $\mathrm{CI} \rightarrow \mathrm{PIV}$ & 0.253 & 0.068 & *** & $\mathrm{H} 4$ & $\mathrm{POE} \rightarrow \mathrm{CI}$ & & & \\
\hline & $\mathrm{FI} \rightarrow \mathrm{PIV}$ & 0.067 & 0.077 & $\mathrm{n}$ & & $\mathrm{POE} \rightarrow \mathrm{FI}$ & 0.247 & 0.071 & $* * *$ \\
\hline & $\mathrm{AI} \rightarrow \mathrm{PIV}$ & 0.231 & 0.074 & $* * *$ & & $\mathrm{POE} \rightarrow \mathrm{AI}$ & 0.230 & 0.081 & $* *$ \\
\hline $\mathrm{H} 2$ & $\mathrm{PIV} \rightarrow \mathrm{SAT}$ & 0.202 & 0.066 & $* *$ & $\mathrm{H} 5$ & $\mathrm{PSEE} \rightarrow \mathrm{CI}$ & 0.436 & 0.074 & $* * *$ \\
\hline \multirow[t]{3}{*}{$\mathrm{H} 3$} & $\mathrm{CI} \rightarrow \mathrm{SAT}$ & 0.243 & 0.068 & $* * *$ & & $\mathrm{PSEE} \rightarrow \mathrm{FI}$ & 0.293 & 0.071 & $* * *$ \\
\hline & $\mathrm{FI} \rightarrow \mathrm{SAT}$ & 0.169 & 0.067 & $* *$ & & $\mathrm{PSEE} \rightarrow \mathrm{AI}$ & 0.315 & 0.072 & $* * *$ \\
\hline & $\mathrm{AI} \rightarrow \mathrm{SAT}$ & 0.026 & 0.072 & n.s. & & $p<0.05 \quad * *$ & $<0.01$ & $* * * p<0$. & 001 \\
\hline
\end{tabular}




\section{Conclusion}

The results from the survey generally support our proposition that a blogger treats one's blog as a performing stage to actively present one's identity to a public audience of readers [6,9]. This is accomplished with the aid of the various blog design features as props. Through this process of impression management, a blogger can indeed achieve the goal of expressing one's life and sharing one's expertise and experience. Consequently, the blogger derives personal satisfaction with the blogging process.

The main theoretical contribution of this study is providing a plausible explanation as to why and how the majority of bloggers seek to express their life, and to share their expertise and experience. By adopting a process model, instead of a variance model, we provide a rich insight into the antecedent and consequential factors involved in the impression management process. This model may be adapted to explain why and how individuals use social computing technologies that have the capability to reflect one's identity, e.g., social networking sites and virtual worlds.

Practically, our research findings emphasize the importance for third party blog hosting service providers to make available a well-balanced basket of content, functional and aesthetic blog design features to their bloggers. This will help the majority of the bloggers in their impression management endeavor and thus leading to greater satisfaction. Presumably, this will improve the acquisition and retention of new and existing bloggers.

\section{References}

1. Technorati State of the Blogosphere (2009), http: //technorati.com/blogging/feature/state-of-theblogosphere-2009

2. Blood, R.: How Blogging Software Reshapes the Online Community. Communications of the ACM 47(12), 53-55 (2004)

3. Nardi, B.A., Schiano, D.J., Gumbrecht, M., Swarth, L.: Why We Blog. Communications of the ACM 47(12), 41-46 (2004)

4. Moon, J., Li, J.P., Sanders, G.L.: The Role of Virtual Social Identity through Blog Use in Social Life. In: 12th AMCIS, Mexico, pp. 4085-4095 (2006)

5. Leary, M.R., Kowalski, R.M.: Impression Management: A Literature Review and TwoComponent Model. Psychological Bulletin 107(1), 34-47 (1990)

6. Goffman, E.: The Presentation of Self in Everyday Life. Doubleday, New York (1959)

7. Wynn, E., Katz, J.E.: Hyperbole over Cyberspace: Self-Presentation and Social Boundaries in Internet Home Pages and Discourse. The Information Society 13(4), 297327 (1997)

8. Schau, H.J., Gilly, M.C.: We are What We Post? Self Presentation in Personal Web Space. J. Consumer Research 30(3), 385-404 (2003)

9. Vazire, S., Gosling, S.D.: e-Perceptions: Personality Impressions Based on Personal Websites. J. Personality and Social Psychology 87(1), 123-132 (2004)

10. Bortree, D.S.: Presentation of Self on the Web: An Ethnographic Study of Teenage Girls' Weblogs. Education, Communication \& Information 5(1), 25-39 (2005) 
11. Leary, M.R.: Understanding Social Anxiety: Social, Personality, Clinical Perspectives. Sage, Beverly Hills (1983)

12. Maddux, J.E., Norton, L.W., Leary, M.R.: Cognitive Components of Social Anxiety: An Investigation of the Integration of Self-Presentation Theory and Self-Efficacy Theory. J. Social and Clinical Psychology 6(2), 180-190 (1988)

13. Preece, J., Maloney-Krichmar, D.: Online Communities. In: Jacko, J., Sears, A. (eds.) Handbook of Human-Computer Interaction, pp. 596-620. Lawrence Erlbaum Associates Inc., New Jersey (2003)

14. Walker, K.: It's Difficult to Hide It: The Presentation of Self on Internet Home Pages. Qualitative Sociology 23(1), 99-120 (2000)

15. Walther, J.B.: Computer-Mediated Communication: Impersonal, Interpersonal, and Hyperpersonal Interaction. Communication Research 23, 3-43 (1996)

16. Ma, M., Agarwal, R.: Through a Glass Darkly: Information Technology Design, Identity Verification, and Knowledge Contribution in Online Communities. Information Systems Research 18(1), 42-67 (2007)

17. Swann, W.B., Polzer, J.T., Seyle, D.C., Ko, S.J.: Finding Value in Diversity: Verification of Personal and Social Self-Views in Diverse Groups. Academy of Management Review 29(1), 9-27 (2004)

18. De La Ronde, C., Swann, W.B.: Partner Verification: Restoring Shattered Images of Our Intimates. J. Personality and Social Psychology 75(2), 374-382 (1998)

19. Jensen, C., Davis, J., Farnham, S.: Finding Others Online: Reputation Systems for Social Online Spaces. In: SIGCHI Conference on Human Factors in Computing Systems, Minnesota, pp. 447-454 (2002)

20. Newcomb, T.M.: The Acquaintance Process. Holt, Rinehart and Winston, New York (1961)

21. Briggs, R.O., Reinig, B.A., de Vreede, G.J.: Meeting Satisfaction for TechnologySupported Groups. Small Group Research 37(6), 585-611 (2006)

22. Reinig, B.A.: Towards an Understanding of Satisfaction with the Process and Outcomes of Teamwork. J. Management Information Systems 19(4), 65-83 (2003)

23. Compeau, D.R., Higgins, C.A.: Computer Self-Efficacy: Development of a Measure and Initial Test. MIS Quarterly 19(2), 189-211 (1995)

24. Hsu, M.-H., Chiu, C.-M.: Internet Self-Efficacy and Electronic Service Acceptance. Decision Support Systems 38, 369-381 (2004)

25. Leary, M.R.: Understanding Social Anxiety: Social, Personality, Clinical Perspectives. Sage, Beverly Hills (1983)

26. Stone, B.: Blogging: Genius Strategies for Instant Web Content. New Riders Publishing, Indiana (2003)

27. Callero, P.L.: Role-Identity Salience. Social Psychology Quarterly 48(3), 203-215 (1985)

28. Bhattacherjee, A.: Understanding Information Systems Continuance: An ExpectationConfirmation Model. MIS Quarterly 25(3), 351-370 (2001) 